\title{
KUALITAS SELAI LEMBARAN KOMBINASI UMBI BIT MERAH (Beta vulgaris L. var. rubra L.) DAN EKSTRAK PEKTIN DAMI NANGKA (Artocarpus heterophyllus Lamk.)
}

\author{
(Quality of Fruit Leather with Combination of Red Beet (Beta vulgaris L. \\ var. rubra L.) and Extract from Jackfruit Straw (Artocarpus heterophyllus \\ Lamk.))
}

\author{
Intan Diah Paramita*a, Franciscus Sinung Pranata ${ }^{a}$, Yuliana Reni Swastia \\ aFakultas Teknobiologi, Universitas Atma Jaya Yogyakarta, Indonesia \\ ${ }^{*}$ Penulis Korespondensi \\ Email: intandiah558@gmail.com
}

\begin{abstract}
Jackfruit straw (Artocarpus heterophyllus Lamk.) is a potential source of pectin in the formation of fruit leather gel in combination with red beet (Beta vulgaris L. var rubra L.), thus producing attractive fruit leather. The purpose of this research was to know the influence of combination of red beet and extract pectin from jackfruit straw on th quality (chemical, physical, microbiological, and organoleptic) of fruit leather, and to determine the right combination of red beet and extract pectin from jackfruit straw to produce the best quality fruit leather. The results showed that the combination of red beet and extract pectin from jackfruit straw had significantly effect on water content, ash content, crude fiber, soluble dietary fiber, dissolved solids, tritatable acidity, texture analysis, but the effect is not significantly different to the color analysis, microbiological analysis which included Total Plate Count (TPC) and mold yeast. Fruit leather with combination of red beet compared to extract pectin from jackfruit straw $70: 82,5$ is the best quality with chemical characteristics include water content $8,27 \%$, ash content $1,47 \%$, crude fiber $2,35 \%$, soluble dietary fiber $6,37 \%$, pectin content $1,43 \%$, dissolved solid $83,10 \%$, tritatable acidity $0,82 \%$, physical characterictics include texture $542,17 \mathrm{~g}$, with the pink colored of fruit leather. Microbiological characteristics include Total Plate Count (TPC) 1,79 logCFU/g, and mold yeast 1,46 logCFU/g which most parameter meet the Indonesian National Standard.
\end{abstract}

Keywords: Fruit Leather, Jackfruit Straw, Pectin, Red Beet

\begin{abstract}
ABSTRAK
Dami nangka (Artocarpus heterophyllus Lamk.) merupakan sumber pektin yang berpotensi dalam pembentukan gel selai lembaran dengan dikombinasikan bersama umbi bit merah (Beta vulgaris L. var rubra L.), sehingga menghasilkan selai lembaran yang menarik. Tujuan penelitian untuk mengetahui pengaruh kombinasi umbi bit merah dan ekstrak pektin dami nangka terhadap kualitas (kimia, fisik, mikrobiologi, dan organoleptik), serta menentukan kombinasi umbi bit merah dan ekstrak pektin dami nangka yang tepat untuk menghasilkan selai lembaran kualitas terbaik. Hasil penelitian menunjukkan bahwa kombinasi umbi bit merah dan ekstrak pektin dami nangka memberi pengaruh nyata terhadap kadar air, abu, serat kasar, serat larut, pektin, total padatan terlarut, total asam tertitrasi, analisis tekstur, serta memberi pengaruh tidak berbeda nyata terhadap analisis warna, analisis mikrobiologi meliputi angka lempeng total (ALT) dan kapang khamir. Selai lembaran dengan kombinasi umbi bit merah berbanding ekstrak pektin dami nangka $70: 82,5$ merupakan kualitas terbaik dengan karakteristik kimia meliputi kadar air $8,27 \%$, abu $1,47 \%$, serat kasar $2,35 \%$, serat larut $6,37 \%$, pektin $1,43 \%$, total padatan terlarut $83,10 \%$, total asam tertitrasi $0,82 \%$, karakteristik fisik meliputi tekstur sebesar $542,17 \mathrm{~g}$ dan
\end{abstract}


Jurnal Teknologi Pangan dan Gizi

Journal of Food Technology and Nutrition

Vol 20 (1): 52-62, 2021.

dihasilkan selai lembaran berwarna merah muda. Karakteristik mikrobiologi meliputi ALT sebesar 1,79 logCFU/gram, kapang khamir 1,46 logCFU/gram dan sebagian besar telah memenuhi Standar Nasional Indonesia.

Kata Kunci: Dami Nangka, Pektin, Selai Lembaran, Umbi Bit Merah

\section{PENDAHULUAN}

Selai lembaran merupakan selai berbentuk semi padat, dicetak dengan ukuran yang disesuaikan dengan ukuran roti tawar pada umumnya sehingga dapat memudahkan pengguna dalam penyajian makanan, terutama untuk orang yang sering mengonsumsi roti (Putri, 2016). Menurut deMan dan Gupta (1989), kandungan pektin supaya membentuk gel terbaik pada pembuatan selai sebesar $0,2-1,5 \%$. Selai lembaran berasal dari pengeringan bubur buah (puree) menggunakan oven (Puspasari et al., 2005), memiliki kadar air $10-15 \%$, berbentuk lembaran tipis ( $\pm 2-3$ $\mathrm{mm}$ ), dan memiliki rasa khas sesuai buah yang digunakan (Historiasih, 2010). Selai lembaran berkualitas baik jika memiliki tekstur kenyal, konsisten, dapat ditarik dari permukaan plastik tanpa patah, dapat digulung, dan memiliki bentuk yang utuh atau tidak sobek (Delong, 1992).

Nangka dikenal sebagai buah majemuk (sinkarpik) dan tersusun atas banyak kumpulan buah (Sunaryono, 2005). Menurut Badan Pusat Statistik Republik Indonesia (2015), produksi nangka tahun 2014 sebesar 644.297 ton, sedangkan tahun 2015 sebesar 699.495 ton. Dami nangka berada pada kisaran 40 - 50\% dari limbah yang dihasilkan (Hasibuan et al., 2017). Dami nangka adalah sekumpulan serabut putih yang membungkus daging buah nangka (Putra, 2010). Sifat fisik maupun kimia dami nangka menyerupai buah nangka, seperti kandungan air, serat, pektin, protein, lemak, karbohidrat, dan vitamin C (Siti et al., 2016).
Hasil penelitian Tarmizi (2011), kandungan pektin dami nangka cukup tinggi sekitar 2,38\%. Kombinasi dengan bahan lain sangat diperlukan dalam pembuatan selai lembaran dari dami nangka karena diduga selai lembaran yang dihasilkan akan memiliki warna yang kurang menarik. Menurut Lestario (2017), umbi bit merah adalah penghasil pigmen betalain yang merupakan sumber pewarna alami yang dapat digunakan sebagai pewarna makanan dan minuman. Selain memiliki warna yang menarik, umbi bit merah memiliki karakteristik lain yaitu rasa manis dan rasa yang dikenal seperti tanah atau "earthy taste" (Chasparinda et al., 2014). Penelitian ini bertujuan untuk mengetahui pengaruh kombinasi umbi bit merah (Beta vulgaris L. var. rubra L.) dan ekstrak pektin dami nangka (Artocarpus heterophyllus Lamk.) sehingga dapat menghasilkan selai lembaran dengan sifat kimia, fisik, mikrobiologi, dan organoleptik terbaik dan disukai konsumen.

\section{BAHAN DAN METODE}

\section{Bahan}

Bahan - bahan yang digunakan antara lain adalah dami nangka mengkal, umbi bit merah, gula pasir (Gulaku), asam sitrat (Gajah), agar - agar bubuk (Swallow Globe Brand), $\mathrm{HCl}$ pekat (Chemix), medium Plate Count Agar (PCA), medium Potato Dextrose Agar (PDA), dan celit (Chemix).

\section{Preparasi Bahan Ekstrak Dami Nangka}

Dami nangka dilakukan blansir di suhu $75^{\circ} \mathrm{C}$ selama \pm 5 menit, kemudian diiris tipis. Dami nangka ditambah air dengan 
perbandingan 1 : 2 (100 gram dami nangka : $200 \mathrm{ml}$ air). Ekstraksi pektin dari dami nangka dilakukan dengan merebus dami nangka dalam panci dengan suhu $70-80^{\circ} \mathrm{C}$ selama 45 menit. Air hasil rebusan (ekstrak pektin) dipisahkan dengan saringan (Putri dkk., 2013 dengan modifikasi).

\section{Preparasi Bahan Bubur Umbi Bit Merah}

Kulit umbi bit merah dikupas, dagingnya dibersihkan, dan dipotong kecil - kecil. Air disiapkan ke dalam panci dan dipanaskan sampai air mendidih. Setelah itu, daging umbi bit merah dikukus selama 30 menit. Daging umbi bit merah kemudian dihancurkan dengan handblender (Jalias, 2018 dengan modifikasi).

\section{Metode Pembuatan Selai Lembaran}

Bubur umbi bit merah ditambahkan dengan ekstrak pektin dami nangka sesuai dengan formulasi. Formulasi umbi bit merah : ekstrak pektin dami nangka yaitu 70 gram : $0 \mathrm{ml}, 70$ gram : $27,5 \mathrm{ml}, 70$ gram : $55 \mathrm{ml}$, dan 70 gram : $82,5 \mathrm{ml}$. Adonan ditambah dengan gula, asam sitrat, dan agar yang telah dilarutkan dalam air minum kemasan sesuai dengan formulasi, kemudian dimasak selama 5 menit. Adonan selai lembaran dicetak di dalam loyang, lalu dimasukkan ke dalam oven selama 6 jam dengan suhu $60^{\circ} \mathrm{C}$. Selai lembaran yang telah jadi dipotong - potong dengan ukuran 8 x 8 cm (Hasibuan dkk., 2017 dengan modifikasi).

\section{Analisis Statistik}

Analisis data yang digunakan adalah Anova (Analysis of Variance) dan dilanjutkan menggunakan DMRT (Duncan's Multiple Range Test) untuk mengetahui letak beda nyata antar perlakuan menggunakan tingkat kepercayaan yang digunakan 95\%. Data yang diperoleh kemudian diproses menggunakan program SPSS versi 22 (Gasperz, 1991).

\section{HASIL DAN PEMBAHASAN}

Hasil analisis kandungan gizi umbi bit merah dan dami nangka

Hasil analisis kandungan gizi umbi bit merah dan dami nangka dapat dilihat pada Tabel 1 dan 2 (Lampiran).

Hasil analisis kimia, fisik, mikrobiologi, dan organoleptik selai lembaran

Analisis kadar air selai lembaran

Kadar air maksimum yang boleh terkandung dalam selai sebesar 35\% (Standar Industri Indonesia, 1978). Berdasarkan Standar Industri Indonesia, kadar air selai lembaran kombinasi umbi bit merah dan ekstrak pektin dami nangka pada semua perlakuan memenuhi ketentuan batas maksimum yang telah ditetapkan. Berdasarkan pengujian kadar air, dapat diketahui bahwa semakin banyak penambahan ekstrak pektin dami nangka, maka kadar air selai lembaran semakin rendah. Air bebas dapat diikat pektin pada bahan sehingga kadar air pada selai lembaran menurun (Jalias, 2018). Pektin yang ditambahkan ke dalam makanan dapat memantapkan sistem dispersi yang homogen dan meningkatkan viskositas bahan, serta mengurangi air bahan tersebut (Estiasih dan Ahmadi, 2009).

\section{Analisis kadar abu selai lembaran}

Hasil uji kadar abu, menunjukkan bahwa semakin banyak penambahan ekstrak pektin dami nangka, maka kadar abu selai lembaran semakin tinggi. Kandungan mineral sangat bermacam - macam pada berbagai jenis buah, namun tergantung pada curah hujan, kondisi tanah, dan pemberian pupuk (deMan, 1997). Apabila air yang terikat semakin banyak, maka kandungan abu semakin meningkat karena di dalam air juga terkandung banyak garam mineral seperti $\mathrm{Ca}, \mathrm{Na}, \mathrm{K}$, dan $\mathrm{Cl}$. Kandungan mineral umbi bit merah cukup banyak dan berdasarkan kandungan yang paling tinggi ke rendah yaitu natrium, kalium, magnesium, kalsium, mangan, besi, seng, dan tembaga (Odoh dan Okoro, 2013). Kandungan mineral nangka muda 
Jurnal Teknologi Pangan dan Gizi Journal of Food Technology and Nutrition

Vol 20 (1): 52-62, 2021.

Tabel 1. Hasil Analisis Kandungan Gizi Umbi Bit Merah dan Dami Nangka

\begin{tabular}{lcc}
\hline \multicolumn{1}{c}{ Kandungan Gizi } & \multicolumn{2}{c}{ Hasil Analisis } \\
\cline { 2 - 3 } & Umbi Bit Merah & Dami Nangka \\
\hline Kadar Air & $89,72 \%$ & $81,75 \%$ \\
Kadar Abu & $1,07 \%$ & $1,20 \%$ \\
Kadar Serat Kasar & $1,65 \%$ & $1,35 \%$ \\
Kadar Serat Larut & $3,48 \%$ & $7,10 \%$ \\
Kadar Pektin & - & $0,44 \%$ \\
Total Asam Tertitrasi & $0,30 \%$ & $0,48 \%$ \\
\hline
\end{tabular}

Keterangan: (-) tidak diuji

Tabel 2. Kadar Air Selai Lembaran Kombinasi Umbi Bit Merah dan Ekstrak Pektin Dami Nangka

\begin{tabular}{cc}
\hline Perbandingan Umbi Bit Merah : Ekstrak Pektin Dami Nangka & Kadar Air (\%) \\
\hline K $(70: 0)$ & $9,41 \pm 0,12^{\mathrm{a}}$ \\
A $(70: 27,5)$ & $9,07 \pm 0,17^{\mathrm{b}}$ \\
B $(70: 55)$ & $8,70 \pm 0,28^{\mathrm{c}}$ \\
C $(70: 82,5)$ & $8,27 \pm 0,06^{\mathrm{d}}$ \\
\hline
\end{tabular}

Keterangan: Angka yang diikuti huruf yang sama pada kolom yang sama menunjukkan tidak adanya beda nyata, pada tingkat kepercayaan $95 \%$

Tabel 3. Kadar Abu Selai Lembaran Kombinasi Umbi Bit Merah dan Ekstrak Pektin Dami Nangka

\begin{tabular}{cc}
\hline Perbandingan Umbi Bit Merah : Ekstrak Pektin Dami Nangka & Kadar Abu (\%) \\
\hline K $(70: 0)$ & $1.19 \pm 0,07^{\mathrm{a}}$ \\
A $(70: 27,5)$ & $1.23 \pm 0,00^{\mathrm{a}}$ \\
B $(70: 55)$ & $1.37 \pm 0,06^{\mathrm{b}}$ \\
C $(70: 82,5)$ & $1.47 \pm 0,05^{\mathrm{c}}$ \\
\hline
\end{tabular}

Keterangan: Angka yang diikuti huruf yang sama pada kolom yang sama menunjukkan tidak adanya beda nyata, pada tingkat kepercayaan $95 \%$

Tabel 4. Kadar Serat Kasar Selai Lembaran Kombinasi Umbi Bit Merah dan Ekstrak Pektin Dami Nangka

\begin{tabular}{cc}
\hline Perbandingan Umbi Bit Merah : Ekstrak Pektin Dami Nangka & Kadar Serat Kasar (\%) \\
\hline K $(70: 0)$ & $0,78 \pm 0,05^{\mathrm{a}}$ \\
A $(70: 27,5)$ & $1,20 \pm 0,07^{\mathrm{b}}$ \\
B $(70: 55)$ & $1,61 \pm 0,10^{\mathrm{c}}$ \\
C $(70: 82,5)$ & $2,35 \pm 0,13^{\mathrm{d}}$
\end{tabular}

Keterangan: Angka yang diikuti huruf yang sama pada kolom yang sama menunjukkan tidak adanya beda nyata, pada tingkat kepercayaan $95 \%$

berdasarkan kandungan yang paling tinggi ke rendah yaitu kalsium, fosfor, dan besi (Pitojo, 2017).

\section{Analisis serat kasar selai lembaran}

Serat selai buah memiliki syarat mutu produk yaitu normal atau positif mengandung serat (Badan Standarisasi Nasional Indonesia, 2008). Berdasarkan Badan Standarisasi Nasional Indonesia, selai lembaran kombinasi umbi bit merah dan ekstrak pektin dami nangka pada semua perlakuan positif mengandung serat kasar, sehingga dapat dikatakan bahwa 
produk selai lembaran yang dihasilkan memenuhi syarat Standar Nasional Indonesia. Semakin banyak penambahan ekstrak pektin dami nangka, maka kadar serat kasar selai lembaran semakin tinggi. Hal ini dapat dikarenakan kandungan serat kasar bahan baku ekstrak pektin dami nangka berkontribusi dalam peningkatan produk selai lembaran yang dihasilkan. Peningkatan kadar serat kasar juga dapat dikarenakan pada proses pemasakan selai lembaran, dilakukan penambahan agar agar ke dalam adonan selai lembaran. Adanya penambahan hidrokoloid seperti agar - agar dapat meningkatkan kadar serat pada produk (Khairunnisa dkk., 2015).

\section{Analisis serat larut selai lembaran}

Serat selai buah memiliki syarat mutu produk yaitu normal atau positif mengandung serat (Badan Standarisasi Nasional Indonesia, 2008). Berdasarkan Badan Standarisasi Nasional Indonesia, selai lembaran kombinasi umbi bit merah dan ekstrak pektin dami nangka pada semua perlakuan positif mengandung serat larut, sehingga dapat dikatakan bahwa produk selai lembaran yang dihasilkan memenuhi syarat Standar Nasional Indonesia. Semakin banyak penambahan ekstrak pektin dami nangka, maka kadar serat larut selai lembaran semakin tinggi. Hal ini dapat dikarenakan kandungan serat larut bahan baku dari selai lembaran yaitu umbi bit merah dan ekstrak pektin dami nangka yang tinggi, dengan masing masing bahan baku secara berurutan memiliki kadar serat larut sebesar $3,48 \%$ dan $7,10 \%$.

Pektin termasuk ke dalam serat pangan larut, sehingga semakin tinggi konsentrasi pektin, maka kadar serat larut semakin meningkat (Lattimer dan Haub, 2010). Asupan serat harus berkisar antara $20-35$ gram per hari untuk manfaat yang optimal (Widyaningsih dkk., 2017). Selai lembaran kombinasi umbi bit merah dan ekstrak pektin dami nangka perlakuan $\mathrm{C}(70: 82,5)$ mengandung serat larut sebesar 1,274 gram. Konsumsi selai lembaran perlakuan
C telah memenuhi $6,37 \%$ dari anjuran asupan serat.

\section{Analisis kadar pektin selai lembaran}

Pembuatan selai dengan konsistensi gel yang cocok yaitu dengan kadar pektin sebesar 0,75 - 1,5\% (Muchtadi, 1997 dan Buckle dkk., 1987). Berdasarkan uji kadar pektin, dapat diketahui bahwa semakin banyak ekstrak pektin dami nangka, maka kadar pektin selai lembaran semakin tinggi. Kadar pektin yang tinggi juga dapat dikarenakan dami nangka yang diambil adalah dami nangka pada buah nangka yang memiliki tingkat kematangan yaitu buah mengkal. Pektin banyak terdapat di buah mengkal sehingga pada pembuatan selai, sangat dianjurkan adanya penggunaan buah matang dan buah mengkal (Noviai, 2017).

Berdasarkan analisis bahan baku awal ekstrak pektin dami nangka memiliki kadar pektin sebesar 0,44\%. Hasil kadar pektin selai lembaran lebih tinggi dibandingkan dengan hasil kadar pektin bahan baku ekstrak pektin dami nangka. Hal tersebut mengindikasikan bahwa penambahan umbi bit merah pada pembuatan selai lembaran berkontribusi dalam menambah kadar pektin pada selai lembaran yang dihasilkan.

\section{Analisis kadar total padatan terlarut selai lembaran}

Padatan terlarut pada selai buah yaitu minimal sebesar 65\% (Badan Standarisasi Nasional Indonesia, 2008). Berdasarkan Badan Standarisasi Nasional Indonesia, kadar total padatan terlarut selai lembaran kombinasi umbi bit merah dan ekstrak pektin dami nangka pada semua perlakuan memenuhi ketentuan batas minimum yang telah ditetapkan. Berdasarkan analisis kadar total padatan terlarut dapat diketahui bahwa semakin banyak penambahan ekstrak pektin dami nangka, maka kadar total padatan terlarut selai lembaran semakin tinggi. Hal ini dapat dikarenakan adanya pektin dapat memengaruhi kadar total padatan terlarut. Selain itu, adanya penambahan bahan lain dalam proses 
Jurnal Teknologi Pangan dan Gizi Journal of Food Technology and Nutrition

Vol 20 (1): 52-62, 2021.

Tabel 5. Kadar Serat Larut Selai Lembaran Kombinasi Umbi Bit Merah dan Ekstrak Pektin Dami Nangka

\begin{tabular}{cc}
\hline Perbandingan Umbi Bit Merah : Ekstrak Pektin Dami Nangka & Kadar Serat Larut (\%) \\
\hline K $(70: 0)$ & $1,91 \pm 0,22^{\mathrm{a}}$ \\
A $(70: 27,5)$ & $3,17 \pm 0,18^{\mathrm{b}}$ \\
B $(70: 55)$ & $4,37 \pm 0,10^{\mathrm{c}}$ \\
C $(70: 82,5)$ & $6,37 \pm 0,08^{\mathrm{d}}$ \\
\hline
\end{tabular}

Keterangan: Angka yang diikuti huruf yang sama pada kolom yang sama menunjukkan tidak adanya beda nyata, pada tingkat kepercayaan $95 \%$

Tabel 6. Kadar Pektin Selai Lembaran Kombinasi Umbi Bit Merah dan Ekstrak Pektin Dami Nangka

\begin{tabular}{cc}
\hline Perbandingan Umbi Bit Merah : Ekstrak Pektin Dami Nangka & Kadar Pektin (\%) \\
\hline K $(70: 0)$ & $0,81 \pm 0,02^{\mathrm{a}}$ \\
A $(70: 27,5)$ & $0,88 \pm 0,06^{\mathrm{a}}$ \\
B $(70: 55)$ & $1,31 \pm 0,04^{\mathrm{b}}$ \\
C $(70: 82,5)$ & $1,43 \pm 0,04^{\mathrm{c}}$ \\
\hline
\end{tabular}

Keterangan: Angka yang diikuti huruf yang sama pada kolom yang sama menunjukkan tidak adanya beda nyata, pada tingkat kepercayaan $95 \%$

Tabel 7. Kadar Total Padatan Terlarut Selai Lembaran Kombinasi Umbi Bit Merah dan Ekstrak Pektin Dami Nangka

\begin{tabular}{cc}
\hline Perbandingan Umbi Bit Merah : Ekstrak Pektin Dami Nangka & Total Padatan Terlarut (\%) \\
\hline K $(70: 0)$ & $70,36 \pm 0,21^{\mathrm{a}}$ \\
A $(70: 27,5)$ & $75,77 \pm 0,90^{\mathrm{a}}$ \\
B $(70: 55)$ & $79,60 \pm 0,73^{\mathrm{b}}$ \\
C $(70: 82,5)$ & $83,10 \pm 0,75^{\mathrm{b}}$ \\
\hline
\end{tabular}

Keterangan: Angka yang diikuti huruf yang sama pada kolom yang sama menunjukkan tidak adanya beda nyata, pada tingkat kepercayaan $95 \%$

Tabel 8. Kadar Total Asam Tertitrasi Selai Lembaran Kombinasi Umbi Bit Merah dan Ekstrak Pektin Dami Nangka

\begin{tabular}{cc}
\hline Perbandingan Umbi Bit Merah : Ekstrak Pektin Dami Nangka & Total Asam Tertitrasi (\%) \\
\hline K $(70: 0)$ & $0,50 \pm 0,01^{\mathrm{a}}$ \\
A $(70: 27,5)$ & $0,56 \pm 0,03^{\mathrm{b}}$ \\
B $(70: 55)$ & $0,72 \pm 0,04^{\mathrm{c}}$ \\
C $(70: 82,5)$ & $0,82 \pm 0,02^{\mathrm{d}}$ \\
\hline
\end{tabular}

Keterangan: Angka yang diikuti huruf yang sama pada kolom yang sama menunjukkan tidak adanya beda nyata, pada tingkat kepercayaan $95 \%$

Tabel 9. Tekstur Selai Lembaran Kombinasi Umbi Bit Merah dan Ekstrak Pektin Dami Nangka

\begin{tabular}{cc}
\hline Perbandingan Umbi Bit Merah : Ekstrak Pektin Dami Nangka & Kekerasan $(\mathrm{g})$ \\
\hline K $(70: 0)$ & $322,67 \pm 36,08^{\mathrm{a}}$ \\
A $(70: 27,5)$ & $340,67 \pm 44,88^{\mathrm{ab}}$ \\
B $(70: 55)$ & $411,67 \pm 32,52^{\mathrm{b}}$ \\
C $(70: 82,5)$ & $542,17 \pm 61,38^{\mathrm{c}}$
\end{tabular}

Keterangan: Angka yang diikuti huruf yang sama pada kolom yang sama menunjukkan tidak adanya beda nyata, pada tingkat kepercayaan $95 \%$ 
pembuatan selai lembaran selain bahan baku utama, seperti gula dan agar - agar.

Pektin dan sukrosa adalah komponen penyusun total padatan terlarut (Novita dkk., 2017). Hidrokoloid yang ditambahkan pada pembuatan selai lembaran dapat berkontribusi pada zat padat yang terlarut dalam air, sehingga kadar zat padat terlarutnya meningkatkan nilai total padatan terlarut (Nugroho dkk., 2016). Penambahan umbi bit merah pada proses pembuatan selai lembaran juga berkontribusi dalam total padatan terlarut, karena umbi bit merah mengandung gula tinggi (Hidayat dkk., 2019).

\section{Analisis kadar total asam tertitrasi selai lembaran}

Hasil kadar total asam tertitrasi pada penelitian Ering dkk. (2015) tentang pembuatan selai lembaran kombinasi buah pepaya dan salak memperoleh hasil kadar total asam tertitrasi sebesar 0,38\%. Hasil penelitian ini tidak jauh berbeda dengan hasil penelitian tersebut, hal ini dikarenakan buah yang dipakai pada penelitian tersebut merupakan buah yang telah matang. Pematangan buah pada umumnya dapat memengaruhi peningkatan jumlah gula sederhana serta menurunkan kadar asam buah (Kurniawan dkk., 2013). Kadar asam organik akan berkurang secara perlahan pada waktu pematangan. Asam organik adalah substrat untuk respirasi, oleh karena itu dengan berkurangnya asam, berhubungan erat dengan fungsi respirasi (Hayati dkk., 2015).

Berdasarkan analisis kadar total asam tertitrasi, dapat diketahui bahwa semakin banyak penambahan ekstrak pektin dami nangka, maka kadar total asam tertitrasi selai lembaran semakin tinggi. Pektin bersifat asam, sehingga menyebabkan kadar total asam tertitrasi semakin meningkat, serta dikarenakan semakin banyaknya gula yang terhidrolisis menjadi asam. Gula, air, dan padatan terlarut seperti asam - asam dapat diikat oleh pektin, sedangkan pektin bersifat asam sehingga dapat menyebabkan total asam semakin meningkat dan dikarenakan semakin banyaknya gula yang terhidrolisis menjadi asam (Ikhwal dkk., 2014). Penambahan asam sitrat bertujuan sebagai penguat rasa alami buah yang hilang selama pemasakan dan pembentukan gel (Sobari, 2018).

\section{Analisis tekstur selai lembaran}

Selai lembaran berkualitas baik jika memiliki tekstur kenyal, konsisten, dapat ditarik dari permukaan plastik tanpa patah, dapat digulung, dan memiliki bentuk yang utuh atau tidak sobek (Delong, 1992). Berdasarkan ciri - ciri yang telah disebutkan, selai lembaran pada penelitian ini telah sesuai dengan kriteria tersebut di semua perlakuan. Berdasarkan analisis kekerasan, dapat diketahui bahwa semakin banyak penambahan ekstrak pektin dami nangka, maka kekerasan selai lembaran semakin tinggi. Hal ini dapat dikarenakan adanya pektin dapat meningkatkan nilai kekerasan dari selai lembaran. Pektin memiliki sifat mengentalkan dan merekatkan dimana di dalam pektin terdapat polisakarida yaitu selulosa, hemiselulosa, pektin, dan lignin yang berperan sebagai penguat tekstur (Jalias, 2018).

Selain pektin, penambahan bahan lain seperti agar - agar dapat menyebabkan gel yang terbentuk menjadi lebih kokoh. Semakin tinggi nilai kekerasan menunjukkan bahwa selai lembaran semakin keras. Faktor yang dapat memengaruhi peningkatan nilai kekerasan yaitu dengan adanya penurunan kadar air. Berkurangnya air bebas dalam selai lembaran menyebabkan produk menjadi lebih padat (Jaya dkk., 2017). Proses pemasakan dalam pembuatan selai lembaran juga dapat memengaruhi nilai kekerasan dari selai lembaran yang dihasilkan (Aritonang, 2013).

\section{Analisis warna selai lembaran}

Hasil analisis warna di semua perlakuan menunjukkan warna yang sama yaitu merah muda. Umbi bit merah dengan takaran yang sama di semua perlakuan merupakan penyebab warna selai lembaran tidak berbeda. Warna makanan dapat 
Jurnal Teknologi Pangan dan Gizi

Journal of Food Technology and Nutrition

Vol 20 (1): 52-62, 2021.

Tabel 10. ALT Selai Lembaran Kombinasi Umbi Bit Merah dan Ekstrak Pektin Dami Nangka

\begin{tabular}{cc}
\hline Perbandingan Umbi Bit Merah : Ekstrak Pektin Dami Nangka & $\begin{array}{c}\text { Angka Lempeng Total } \\
\text { (logCFU/gram) }\end{array}$ \\
\hline K $(70: 0)$ & $2,11 \pm 0,56^{\mathrm{a}}$ \\
A $(70: 27,5)$ & $2,11 \pm 0,97^{\mathrm{a}}$ \\
B $(70: 55)$ & $1,36 \pm 0,10^{\mathrm{a}}$ \\
C $(70: 82,5)$ & $1,79 \pm 0,84^{\mathrm{a}}$ \\
\hline
\end{tabular}

Keterangan: Angka yang diikuti huruf yang sama pada kolom yang sama menunjukkan tidak adanya beda nyata, pada tingkat kepercayaan $95 \%$

Tabel 11. Kapang Khamir Selai Lembaran Kombinasi Umbi Bit Merah dan Ekstrak Pektin Dami Nangka

\begin{tabular}{cc}
\hline Perbandingan Umbi Bit Merah : Ekstrak Pektin Dami Nangka & $\begin{array}{c}\text { Kapang dan Khamir } \\
\text { (logCFU/gram) }\end{array}$ \\
\hline K $(70: 0)$ & $1,90 \pm 0,18^{\mathrm{a}}$ \\
A $(70: 27,5)$ & $1,96 \pm 0,59^{\mathrm{a}}$ \\
$\mathrm{B}(70: 55)$ & $1,36 \pm 0,32^{\mathrm{a}}$ \\
C $(70: 82,5)$ & $1,36 \pm 0,32^{\mathrm{a}}$ \\
\hline Keterangan: Angka yang diikuti huruf yang sama pada kolom yang sama menunjukan
\end{tabular}

Keterangan: Angka yang diikuti huruf yang sama pada kolom yang sama menunjukkan tidak adanya beda nyata, pada tingkat kepercayaan $95 \%$

Tabel 12. Nilai Rata - Rata Uji Organoleptik Selai Lembaran Kombinasi Umbi Bit Merah dan Ekstrak Pektin Dami Nangka

\begin{tabular}{cccccc}
\hline $\begin{array}{c}\text { Perbandingan Umbi Bit } \\
\text { Merah : Ekstrak Pektin Dami } \\
\text { Nangka }\end{array}$ & Warna & Aroma & Rasa & Tekstur & Rata - Rata \\
\hline K $(70: 0)$ & 2,47 & 2,37 & 2,33 & 2,40 & 2,39 \\
A $(70: 27,5)$ & 2,17 & 2,50 & 2,83 & 2,53 & 2,51 \\
B $(70: 55)$ & 2,53 & 1,97 & 1,77 & 2,07 & 2,08 \\
C $(70: 82,5)$ & 2,83 & 3,17 & 3,07 & 3,00 & $\mathbf{3 , 0 2}$ \\
\hline
\end{tabular}


Gambar 1. Kenampakan Warna Selai Lembaran Kombinasi Umbi Bit Merah dan Ekstrak Pektin Dami Nangka

disebabkan oleh pigmen alami atau pewarna. Pigmen dalam makanan dan pigmen yang terbentuk pada proses pemanasan serta penyimpanan dapat digolongkan sebagai pewarna alami (deMan, 1997). Umbi bit merah adalah salah satu penghasil pigmen betalain yang merupakan sumber pewarna alami yang biasa digunakan sebagai pewarna makanan dan minuman (Lestario, 2017).

Analisis angka lempeng total selai lembaran

Selai buah memiliki ketentuan cemaran mikrobia angka lempeng total dengan batas 
maksimum 3 logCFU/gram (Badan Standarisasi Nasional Indonesia, 2008). Berdasarkan standar tersebut, dapat diketahui bahwa selai lembaran kombinasi umbi bit merah dan ekstrak pektin dami nangka di semua perlakuan telah memenuhi standar batas maksimum cemaran mikrobia angka lempeng total yang telah ditetapkan oleh Badan Standarisasi Nasional Indonesia. Proses pemasakan dan pengovenan selai lembaran dapat mengurangi jumlah cemaran mikrobia terutama mikrobia yang tidak tahan terhadap panas. Penambahan gula pada pembuatan selai lembaran dapat mengurangi cemaran mikrobia. Kadar gula tinggi (minimum 40\%) jika ditambah ke dalam bahan pangan dapat menyebabkan air menjadi terikat sehingga menurunkan aktivitas air dan tidak dapat digunakan mikrobia (Estiasih dan Ahmadi, 2009).

\section{Analisis kapang dan khamir selai lembaran}

Selai buah memiliki ketentuan cemaran mikrobia kapang dan khamir dengan batas maksimum 1,70 logCFU/gram (Badan Standarisasi Nasional Indonesia, 2008). Berdasarkan standar tersebut, dapat diketahui bahwa selai lembaran kombinasi umbi bit merah dan ekstrak pektin dami nangka di semua perlakuan telah memenuhi standar batas maksimum cemaran mikrobia kapang dan khamir yang telah ditetapkan oleh Badan Standarisasi Nasional Indonesia. Adanya pertumbuhan kapang dan khamir dapat dikarenakan bahan baku selai lembaran yang digunakan memiliki peluang menyebabkan tumbuhnya kapang dan khamir yaitu umbi bit merah. Umbi bit merah tumbuh di dalam tanah, sehingga penanganan bahan yang tidak tepat dapat menyebabkan terikutnya kapang dan khamir ke dalam produk. Penambahan gula selain sebagai pengawet, juga dapat menghambat pertumbuhan mikroba perusak makanan jika ditambahkan dalam konsentrasi tinggi (Estiasih dan Ahmadi, 2009).
Kombinasi umbi bit merah dan ekstrak pektin dami nangka memberi pengaruh nyata terhadap kadar air, kadar abu, kadar serat kasar, kadar serat larut, kadar pektin, kadar total padatan terlarut, kadar total asam tertitrasi, analisis tekstur, serta memberi pengaruh yang tidak berbeda nyata terhadap analisis warna, analisis mikrobiologi yang meliputi angka lempeng total (ALT) dan kapang khamir. Selai lembaran dengan kombinasi umbi bit merah berbanding ekstrak pektin dami nangka 70 : 82,5 merupakan kualitas terbaik dengan karakteristik kimia meliputi kadar air 8,27\%, abu $1,47 \%$, serat kasar $2,35 \%$, serat larut $6,37 \%$, pektin $1,43 \%$, total padatan terlarut $83,10 \%$, total asam tertitrasi $0,82 \%$, karakteristik fisik meliputi tekstur sebesar $542,17 \mathrm{~g}$ dan dihasilkan selai lembaran berwarna merah muda. Karakteristik mikrobiologi meliputi ALT sebesar 1,79 logCFU/gram, kapang khamir 1,46 logCFU/gram dan sebagian besar telah memenuhi Standar Nasional Indonesia.Saran pada penelitian ini yaitu perlu dilakukan penambahan konsentrasi ekstrak pektin dami nangka pada pembuatan selai lembaran untuk mendapatkan nilai kekerasan, aroma, dan rasa yang lebih disukai panelis.

\section{DAFTAR PUSTAKA}

Aritonang, P. L. W. B. 2013. Pengaruh konsentrasi pektin dan konsentrasi asam sitrat terhadap karakteristik selai lembaran labu kuning (Cucurbita moschata). Naskah Skripsi S1. Jurusan Teknologi Pangan, Fakultas Teknik, Universitas Pasundan, Bandung.

Badan Pusat Statistik Republik Indonesia. 2015. Statistik Tanaman Buah-Buahan dan Sayuran Tahunan. Badan Pusat Statistik, Jakarta. pp. 12.

Badan Standarisasi Nasional Indonesia. 2008. SNI 3746-2008 Selai Buah. BSN, Jakarta.

\section{KESIMPULAN}


Jurnal Teknologi Pangan dan Gizi

Journal of Food Technology and Nutrition

Vol 20 (1): 52-62, 2021.

Buckle, K. A., Edwards, R. A., Fleet, G. H., dan Wotton, M. 1987. Ilmu Pangan. Universitas Indonesia Press, Jakarta. pp. 66.

Chasparinda, M. E., Martina, A. M. A., dan Kawiji. 2014. Pengaruh penambahan jahe (Zingiber officinale R.) terhadap karakteristik fisikokimia dan organoleptik sari buah bit (Beta vulgaris L.). Jurnal Teknosains Pangan, 3(2), pp. 20-27.

Delong, D. 1992. How to Dry Foods. The Berkley Publishing Group, New York. pp. 36.

deMan, J. M. 1997. Kimia Pangan Edisi Kedua. ITB, Bandung. pp. 22.

deMan, J. M. dan Gupta, S. 1989. Kimia Makanan. ITB Press, Bandung. pp. 29.

Ering, M., Kandou, J., Moningka, J., dan Rawung, D. 2015. Pengaruh proporsi campuran buah pepaya (Carica papaya) dan salak (Salacca zalacca) terhadap sifat sensoris dan kimia fruit leather. Cocos, 6(1), pp. 1-7.

Estiasih, T. dan Ahmadi, K. 2009. Teknologi Pengolahan Pangan. Bumi Aksara, Jakarta. pp. 23.

Gasperz, V. 1991. Metode Perancangan Percobaan. Armico, Bandung. pp. 79.

Hasibuan, S. S., Noviar, H. M. S., dan Akhyar, A. M. P. 2017. Pembuatan "Fruit Leather" buah jeruk manis (Citrus sinensis L.) dengan penambahan dami nangka (Artocarpus heterophyllus). JOM Fakultas Pertanian, 4(2), pp. 1-13.

Hayati, R., Syamsuddin., dan Halimursyadah. 2015. Teknologi Pasca Panen. Program Studi Agroteknologi, Fakultas Pertanian, Universitas Syiah Kuala Press.

Hidayat, F., Anum, F., Dewi, E., dan Sholihati. 2019. Kajian penambahan pasta umbi bit merah (Beta vulgaris L.) dan tepung kacang hijau (Phaseolus radiatus L.) dalam pembuatan roll cookies. Rona Teknik Pertanian, 12(1), pp. 1-11.

Historiasih, R. Z. 2010. Pembuatan fruit leather sirsak - rosella. Naskah Skripsi S1. Universitas Pembangunan Nasional Veteran, Jawa Timur.

Ikhwal, A., Zulkifli, L., dan Sentosa, G. 2014. Pengaruh konsentrasi pektin dan lama penyimpanan terhadap mutu selai nanas lembaran. Jurnal Rekayasa Pangan dan Pertanian, 2(4), pp. 61-70.

Jalias, R. 2018. Pengaruh penambahan sorbitol dan pektin pada pembuatan selai lembaran buah bit (Beta vulgaris L.). Naskah Skripsi S1. Fakultas Pertanian, Universitas Muhamadiyah Sumatera Utara, Medan.

Jaya, D. P., Thomas, I. P. S., dan Erni, S. 2017. Pengaruh konsentrasi agar terhadap karakteristik fisikokimia dan organoleptik selai lembaran apel anna dan rosella. Jurnal Teknologi Pangan dan Gizi, 16(2), pp. 58-65.

Khairunnisa, A., Windi, A., dan Esti, W. 2015. Pengaruh penambahan hidrokoloid (CMC dan agar - agar tepung) terhadap sifat fisik, kimia, dan sensoris fruit leather semangka (Citrullus lanatus (thunb.) Matsum. Et Nakai). Jurnal Teknosains Pangan, 4(1), pp. 1-9.

Kurniawan, D., Sri, T., dan Sri, M. 2013. Pengaruh macam dan kadar kitosan terhadap pematangan dan mutu buah sawo (Manilkara zapota L. van Royen). Vegetalika, 2(2), pp. 21-30.

Lattimer, J. M. dan Haub, M. D. 2010. Effect of dietary fiber and its components on metabolic health. Journal Nutrients, 1(2), pp. 1266-1289. 
Lestario, L. N. 2017. Antosianin: Sifat Kimia, Perannya dalam Kesehatan, dan Prospeknya Sebagai Pewarna Makanan. Gadjah Mada University Press, Anggota IKAPI, Yogyakarta.

Muchtadi, T. R. 1997. Petunjuk Laboratorium Teknologi Proses Pengolahan Pangan. Pusat Antar Universitas Pangan dan Gizi, Institut Pertanian Bogor, Bogor.

Noviai, N. 2017. Pengaruh konsentrasi pektin dan gula terhadap karakteristik selai lembaran campolay (Pouteria campechiana). Naskah Skripsi S1. Program Studi Teknologi Pangan, Universitas Pasundan, Bandung.

Novita, T., Tuti, T., dan Hasanuddin. 2017. Sifat fisik dan kimia marmalade jeruk kalamansi (Citrus microcarpa) : kajian konsentrasi pektin dan sukrosa. Eksakta, 18(2), pp. 164-172.

Nugroho, E. S., Tamaroh, S., dan Setyowati, A. 2006. Pengaruh kosentrasi gum arab dan dekstrin terhadap sifat fisik dan tingkat kesukaan temulawak (Curcuma xanthorhiza Roxb) madu instan. Jurnal Logika, 3(2), pp. 7886.

Odoh, U. E. dan Okoro, E. C. 2013. Quantitative phytochemical, proximate/nutritive composition analysis of Beta vulgaris Linnaeus (Chenopodiaceae). International Journal of Current Research, 5(12), pp. 37233728.

Pitojo, S. 2017. Budi Daya Keluwih. Penerbit Kanisius, Yogyakarta. pp. 44.

Puspasari, K., Fenni, R., dan Steisianasari, M. 2005. Formulasi campuran flower leather dari bunga mawar dengan ekstrak rempah - rempah (cengkeh dan kayu manis) sebagai pangan fungsional kaya antioksidan. Laporan Penelitian.
Departemen Ilmu dan Teknologi Pangan IPB, Bogor.

Putra, I. N. K. 2010. Optimasi proses ekstraksi pektin dami buah nangka (Artocarpus heterophyllus Lamk). Agritech, 30(3), pp. 158-163.

Putri, I. R., Basito, dan Widowati, E. 2013. Pengaruh konsentrasi agar-agar dan karagenan terhadap karakteristik fisik, kimia, dan sensori selai lembaran pisang (Musa paradisiacal L.) varietas raja bulu. Jurnal Teknosains Pangan, 2(3), pp. 112-120.

Putri, A. W. 2016. Pengembangan pasar selai buah lembaran. Naskah Skripsi S1. Fakultas Teknologi Pertanian, IPB, Bogor.

Siti, N., Anita, A., dan Rahmi, N. 2016. Penetapan kadar vitamin $\mathrm{C}$ pada jerami nangka (Artocarpus heterophyllus L.). Jurnal Farmasi Sains dan Praktis, 2(1), pp. 1-5.

Sobari, E. 2018. Teknologi Pengolahan Pangan. Penerbit Andi, Yogyakarta. pp. 65.

Standar Industri Indonesia. 1978. Syarat Mutu Selai Buah SII-0175-173. Dewan Standarisasi Nasional, Jakarta.

Sunaryono. 2005. Berkebun 21 Jenis Tanaman Buah. Penebar Swadaya, Jakarta. pp. 58.

Tarmizi. 2011. Pengaruh tingkat pencampuran daging buah dengan dami nangka terhadap mutu selai lembaran nangka (Artocarpus heterophillus) yang dihasilkan. Naskah Skripsi S1. Program Studi Teknologi Hasil Pertanian, Fakultas Teknologi Pertanian, Universitas Andalan, Padang.

Widyaningsih, T. D., Novita, W., dan Nur, I. P. N. 2017. Pangan Fungsional : Aspek Kesehatan, Evaluasi, dan Regulasi. Universitas Brawijaya Press, Malang. 